Journal of Animal and Veterinary Advances 9 (23): 2940-2946, 2010

ISSN: $1680-5593$

(C) Medwell Journals, 2010

\title{
The Prophet of PIT1 Gene Variation and its Effect on Growth Traits in Chinese Indigeous Goat
}

\author{
${ }^{1}$ T.S. Xu, ${ }^{2}$ J.B. Liu, ${ }^{2}$ D.W. Yao, ${ }^{2}$ H.F. Cai, ${ }^{2}$ H. Chen, ${ }^{1}$ H.L. Zhou and ${ }^{2}$ X.Y. Lan \\ ${ }^{1}$ Key Laboratory of Tropical Crops Germplasm Resources Utilization, \\ Chinese Academy of Tropical Agricultural Sciences, \\ Institute of Tropical Crops Genetic Resources, \\ Ministry of Agriculture, Danzhou, Hainan 571737, China \\ ${ }^{2}$ Shaanxi Key Laboratory of Molecular Biology for Agriculture, \\ College of Animal Science and Technology, Northwest A\&F University, \\ Yangling, 712100 Shaanxi, China
}

\begin{abstract}
Due to the significant influence of GH, PRL and PIT1 mutations on production traits, Prophet of PIT1 (PROP1) regulating them is considered as an important and potential candidate gene for goat growth traits by Marker Assisted Selection (MAS). Using Hin6I PCR-RFLP, this study verified the AF453512: g.1795C >T resulting in GCG (79Ala) > GTA (79Val) withinPROP1 gene in Hainan Black Goat(HNBG). Three genotypes (CC, CT and TT) were observed and their frequencies were $0.310,0.493$ and 0.197 , respectively. The allelic frequencies of allele $\mathrm{C}$ and $\mathrm{T}$ were 0.556 and 0.444 , respectively in analyzed population with Hardy-weinberg equilibrium ( $p>0.05$ ). Combining with the reported genotypic frequencies at Hin6l locus in cashmere goat breeds (IMWC and SBWC), dairy goat breeds ( $\mathrm{Sa}, \mathrm{LS}$ and GZ), genotypic frequency of HNBG population showed significant differences when compared with other goat breeds $(p<0.001)$ as well as significant differences of allelic frequencies between $\mathrm{HNBG}$ and other breeds were revealed ( $\mathrm{p}<0.001$ ), implying that the allele $\mathrm{T}$ possibly was associated with the meat traits and growth traits. Association analysis showed significant relationships between Hin6 polymorphisms and Body Length (BL), Chest Circumferene (ChC), Chest Width (ChW) and Cannon Circumference Index $(\mathrm{CaCl})((\mathrm{p}<0.05)$, suggesting that the $\mathrm{PROP} 1$ gene produced significant influences on growth trait. The individuals with genotype $\mathrm{CT}$ demonstrated better Body Length (BL), Chest Circumferene $(\mathrm{ChC})$ and Cannon Circumference Index $(\mathrm{CaCl})(\mathrm{p}<0.05)$ when compared with those of individuals with genotype $\mathrm{CC}$.
\end{abstract}

Key words: Goat, Prophet of PIT1 (PROP1) gene, Single Nucleotide Polymorphism (SNP), PCR-RFLP, Marker Assisted Selection (MAS), genotype

\section{INTRODUCTION}

In goat industry, growth traits are usually of attractive interest during breeding for its determinant economical value. As know, the growth traits are physiological functions under the control of genetics, gestation, litter size, sex and environmental variables, among which genetics control plays an important and dominant role in it.

Along with the advancement of genomics and biotechnology, goat breeders throw greatly interest on achieving more accurate and efficient selection goal by Marker Assisted Selection (MAS). For the goat, a special polytocous species with limited litter size, MAS plays much more eventful role than other polytocous species such as swine in selection program due to the fact that the growth is greatly associated with litter size (Hua et al., 2009). Generally, finding out and validating the genetic markers of growth traits is the initial and crucial step to establish a MAS system (Allan et al., 2007). As one of the critical paired class homeodomain transcription factor in the somatotropic axis involving hormones, growth factors and other regulatory proteins, the Prophet of PIT1 (PROP1) is specifically expressed in the pituitary gland and plays a direct or indirect key role in the ontogenesis of pituitary gonadotropes, somatotropes, lactotropes and caudomedial thyrotropes (Shibahara et al., 2010; Davis et al., 2010). PROP1 not

Corresponding Author: H.L. Zhou, Key Laboratory of Tropical Crops Germplasm Resources Utilization, Chinese Academy of Tropical Agricultural Sciences, Institute of Tropical Crops Genetic Resources, Ministry of Agriculture, Danzhou, Hainan 571737, China 
only operates the secretion of FSH and $\mathrm{LH}$ but also directly controls the expression of PIT1 regulating the expression of Growth Hormone (GH), Prolactin (PRL) and thyrotropin $\beta$ subunit $\left(\mathrm{TSH}_{\beta}\right)$ genes which directly play important roles in growth, development and metabolism in mammals (Li et al., 1990; Pfaffle et al., 1992; Sun et al., 2002; Shibahara et al., 2010; Davis et al., 2010). The reported findings have revealed that the PROP1 as well as its downstream transcription regulary facotr PIT1 is responsible for a phenotype of Combined Pituitary Hormone Deficiency (CPHD) involving $\mathrm{GH}, \mathrm{PRL}$ and $\mathrm{TSH}_{\beta}$ (Shibahara et al., 2010).

According to the reported findings, human PROP1 gene mutations were revealed to associate with $\mathrm{CPHD}$ (Xekouki et al., 2007). Mice PROP1 gene was apparently responsible for a heritable form of murine pituitary dependent dwarfism (Ames dwarf, df) and the $\mathrm{df}$ phenotype resulted from an apparent failure of initial determination of the PIT1 lineage required for production of $\mathrm{GH}, \mathrm{PRL}$ or TSH resulting in dysmorphogenesis and failure to activate PIT1 gene expression (Wu et al., 1998; Carvalho et al., 2006).

Also, the mutations within GH, PRL and TSH genes are significantly associated with growth and development in mammalian animals (Gupta et al., 2007; Hua et al., 2009; Katoh et al., 2008). Therefore, the PROP1 gene can be considered as an important and potential candidate gene for goat growth trait selection and breeding through MAS. The Prophet of PIT1 (PROP1) gene encodes 226 amino acids and is organized of 3 exons and 2 introns. In domestic animals, bovine PROP1 gene was found to have 5 mutations (Pan et al., 2007) and ovine PROP1 gene was identified to have a silent mutation (Lan et al., 2008) as well as goat PROP1 gene was revealed to present a missense mutation (Lan et al., 2009).

Among them, only one mutation of PROP1 gene in goat was conducted to analyze the association with production traits in cashmere goat breeds and dairy goat breeds, however the effect of this mutation on growth traits in meat goat breeds such as Hainan black goat is unknown. Hainan black goat is one of the numerous meat goat breeds and is reared in Southeast China. It is the well-known breed due to not only their tolerance of crushed feed and the local wet weather but also to their delicous meat flavor. Despite its advantages, this kind of meat goat breed has great flaws with slow growth speed and short status which results in the dramastic shrinking of this goat breed rearing size. Consequently, Hainan black goat is in the brick of the edge of endangered goat breeds. Recently, the government is endevouring to take effective breeding and genetic measures through Marker Assisted Selection (MAS) to enlarge the size of this breed with fast growth speed and high status invoiding the

distinguishing species and wasting genetic resources. Therefore, the purpose of the present study is to verify the polymorphism within the PROP1 gene in Hainan black goat and to test their influence on growth traits in order to set up appropriate genetic improvement programmes and to propose possible clues for the sustainable use of the endangered Chinese indegious goat breed.

\section{MATERIALS AND METHODS}

DNA samples: Genomic DNA samples were obtained from 284 unrelated healthy individuals belonging to Hainan Black Goat (HNBG). Genomic DNA was extracted from ears tissues using standard phenol-chloroform method (Sambrook and Russell, 2002. HNBG populations represented meat breeds and reared in native breeding farms in Zanzhou country of Hainan province, P.R. China, respectively. All goats were 2-3 years old adults. Measurements were taken for all 284 individuals (BW = Body Weight; $\mathrm{BH}=$ Body Height; $\mathrm{BL}=$ Body Length; $\mathrm{ChC}=$ Chest Circumference; $\mathrm{ChD}=$ Chest Depth; $\mathrm{ChW}=$ Chest Width; HuW = Hucklebone Width; $\mathrm{CaC}=$ Cannon Circumference). Body Length Index (BLI), Chest Circumference Index (ChCI), Cannon Circumference Index (CaCI) and Trunk Index (TI) were also calculated. The detailed description data involving the before mentioned body weight and body sizes were shown in Table 1 .

PCR amplification of goat PROP1 gene: Based on ovine PROP1 gene sequence (GenBank accession no. AY533708) and bovine PROP1 gene sequence (GenBank accession no. AF453512), three pairs (P1-P3) of primers were designed to amplify entire coding regions and its flanking regions of goat PROP1 gene.

P1F: 5'-atcaagataccaggcatagagg-3'; P1R: 5'-cccaaag attcac tcaccc-3' (exon 1 and its flanking region, $203 \mathrm{bp}$ ).

Table 1: Mean values and standard deviations or standard errors of the analyzed traits

\begin{tabular}{lccr}
\hline Traits & Mean \pm SD & Skewness \pm SE & Kurtosis \pm SE \\
\hline BW (kg) & $28.377 \pm 6.943$ & $0.286 \pm 0.143$ & $0.070 \pm 0.285$ \\
$\mathrm{BH}(\mathrm{cm})$ & $52.634 \pm 4.158$ & $0.047 \pm 0.143$ & $-0.022 \pm 0.284$ \\
$\mathrm{BL}(\mathrm{cm})$ & $55.885 \pm 4.534$ & $-0.030 \pm 0.143$ & $-0.298 \pm 0.284$ \\
$\mathrm{ChC}(\mathrm{cm})$ & $71.964 \pm 6.454$ & $0.021 \pm 0.143$ & $-0.321 \pm 0.284$ \\
$\mathrm{ChD}(\mathrm{cm})$ & $26.428 \pm 2.378$ & $-0.580 \pm 0.143$ & $1.674 \pm 0.284$ \\
$\mathrm{ChW}(\mathrm{cm})$ & $14.867 \pm 1.858$ & $0.416 \pm 0.143$ & $0.181 \pm 0.284$ \\
$\mathrm{HuW}(\mathrm{cm})$ & $13.661 \pm 1.359$ & $-0.130 \pm 0.143$ & $-0.089 \pm 0.284$ \\
$\mathrm{CaC}(\mathrm{cm})$ & $7.778 \pm 0.731$ & $0.026 \pm 0.143$ & $-0.001 \pm 0.285$ \\
$\mathrm{BLI}(\%)$ & $106.460 \pm 7.907$ & $-0.050 \pm 0.143$ & $-0.103 \pm 0.284$ \\
ChCI (\%) & $136.96 \pm 10.020$ & $0.250 \pm 0.143$ & $0.490 \pm 0.284$ \\
CaCI (\%) & $14.761 \pm 1.560$ & $-2.640 \pm 0.143$ & $26.767 \pm 0.284$ \\
TI (\%) & $128.98 \pm 9.0650$ & $0.939 \pm 0.143$ & $3.224 \pm 0.284$ \\
BW = Body Weitht; BH = Body Height; BL = Body Length; ChC $=$ \\
Chest Circumference; ChD = Chest Depth; ChW = Chest Width; HuW = \\
Hucklebone Width; CaC = Cannon Circumference; BLI = Body Length \\
Index; ChCI = Chest Circumference Index; CaCI = Cannon Circumference \\
Index; TI = Trunk index
\end{tabular}


P2F: 5'-atgtggtctgggatggatg-3'; P2R: 5'-ctggtg aaggtt tggg ttag-3' (exon 2 and its flanking region, 414 bp).

P3F: 5'-ctgatgcggetcttcttc-3'; P3R: 5'-acttt agttcc aggact ttgg-3' (exon 3 and its flanking region, $371 \mathrm{bp}$ ).

The $20 \mu \mathrm{L}$ PCR amplification contained $50 \mathrm{ng}$ of genomic DNA, $10 \mathrm{pM}$ of each primer, dNTPs $(0.2 \mathrm{mM})$, $\mathrm{MgCl}_{2}(1.5 \mathrm{mM})$ and $0.50 \mathrm{U}$ Taq DNA polymerase (MBI, Vilnius and Lithuania). The cycling protocol was $5 \mathrm{~min}$ at $95^{\circ} \mathrm{C}, 35$ cycles of $94^{\circ} \mathrm{C}$ for $30 \mathrm{sec}$, annealing at $61.8^{\circ} \mathrm{C}$, 54.3 and $61.3^{\circ} \mathrm{C}$ for $30 \mathrm{sec}$, respectively, $72^{\circ} \mathrm{C}$ for min with a final extension at $72^{\circ} \mathrm{C}$ for $10 \mathrm{~min}$.

PCR-SSCP and Hin6I PCR-RFLP analysis: Aliquots of $5 \mu \mathrm{L}$ of PCR products were mixed with $5 \mu \mathrm{L}$ of denaturing solution ( $95 \%$ formamide, $25 \mathrm{mM}$ EDTA, 0.025\% xylenecyanole and $0.025 \%$ bromophenol blue) and heated for $10 \mathrm{~min}$ at $98^{\circ} \mathrm{C}$ and chilled on ice. Denatured DNA was subjected to $10 \%$ PAGE $(80 \times 73 \times 0.75 \mathrm{~mm})$ in $1 \mathrm{x}$ TBE buffer and constant voltage $250 \mathrm{~V}$ for $15 \mathrm{~min}$ then $160 \mathrm{~V}$ for $2 \mathrm{~h}$. The gel was stainedwith $0.1 \%$ silver nitrate (Lan et al., $2007 \mathrm{a}, \mathrm{b})$. After the polymorphisms were detected, the PCR products of different electrophoresis patterns were sequenced by the Huada Genetic Sequence Company (Beijing, China). The sequences were analyzed with DNASTAR software (Version 7.10, DNASTAR, Madison, USA).

According to PCR-SSCP analysis only P2 locus demonstrated polymorphic. Therefore, the 8 different PCR products of each polymorphic electrophoresis pattern were sequenced and the polymorphic DNA sequences showed that a Hin6I PCR-RFLP method had verified the reported mutation at $\mathrm{P} 2$ locus (exon 2 and its flanking region) of carpine PROP1 gene (Lan et al., 2009). Aliquots of $20 \mu \mathrm{L}$ PCR products of P2 locus with caprine PROP1 gene were digested with $10 \mathrm{U}$ Hin6I (MBI, Vilnius and Lithuania) following the supplier's directions for buffer condition. The digested products were detected by electrophoresis in $3.0 \%$ agarose gel stained with Ethidium Bromide (EB).

Statistical analysis: Based on the genotypes of Hinб locus in analyzed population, genotype frequencies, allele frequencies and Hardy-Weinberg equilibriums were calculated. According to the Nei methods, population genetic indexes, namely, gene heterozygosity, gene homozygosity, effective allele numbers and PIC (Polymorphism Information Content) were also calculated. Besides, based on the previous reported data from the literature (Lan et al., 2009), differences of genotypic and allelic frequencies among/between the persent analyzed genetic type and others were analyzed using a $\chi^{2}$-test which were performed by SPSS software (version 13.0). The adjusted linear model with fixed effects was used to analyze the relationships between genotypes and body weitht and body sizes in the analyzed breed. The model applied was:

Where:

$$
\mathrm{Y}_{\mathrm{ijk}}=\mathrm{u}+\mathrm{F}_{\mathrm{i}}+\mathrm{G}_{\mathrm{j}}+(\mathrm{FG})_{\mathrm{ij}}+\mathrm{e}_{\mathrm{ijk}}
$$

$\mathrm{Y}_{\mathrm{ijk}}=$ The was the trait measured in each ijkth animal

$\mathrm{u}=$ The overall population mean

$\mathrm{F}_{\mathrm{i}}=$ The fixed effect due to ith farm

$\mathrm{G}_{\mathrm{j}} \quad=$ The fixed effect associated with jth genotype

$(\mathrm{FG})_{\mathrm{ij}}=$ The interaction between ith farm $\mathrm{jth}$ genotype

$\mathrm{e}_{\mathrm{ijk}}=$ The random error

Effects associated with farm, sex and season of birth (spring versus fall) as well as the ages of both dams and sires were not used in the linear model as the preliminary statistical analyses indicated that these effects did not have significant influences on variability of traits in this two breeds.

All the goats were adults so the age did not influence on the body size. The Least Square Means (LSMs) with standard errors and multiple range tests for PROP1 genotypes and traits were calculated.

\section{RESULTS AND DISCUSSION}

\section{Polymorphism of the PROP1 gene in Hainan black goat:} In Hin6I PCR-RFLP analysis, the 414 bp amplified DNA fragment of P2 locus with Hin6I endonuclease digestion showed three fragments $(222,164$ and $28 \mathrm{bp})$ for PROP1-C allele and two fragments (250 and $164 \mathrm{bp}$ ) for PROP1-T allele. So, the genotype CC and TT had three fragments (222, 164 and $28 \mathrm{bp}$ ) and two fragments (250 and $164 \mathrm{bp}$ ), respectively while the heterozygous with genotype CT had four fragments $(250,222,164$ and 28 bp) (Fig. 1). As the 250 and 222 bp fragments could be identified in $3.0 \%$ agarose electrophoresis, this study verified an Hin6I PCRRFLP method for detecting a Ala (GCG) 79Val (GTG) missense mutation.

Three genotypes (CC, CT and TT) were shown in Hin6I PCR-RFLP analysis in analyzed population (Table 2). The frequencies of genotypes CC, CT and TT were $0.310,0.493$ and 0.197 , respectively. Correspondingly, the allelic frequencies of allele $\mathrm{C}$ and $\mathrm{T}$ were 0.556 and 0.444 , respectively. The gene homozygosity of HNBG was equal to 0.5060 as well as effective allele numbers to 1.975. The PIC (polymorphism 


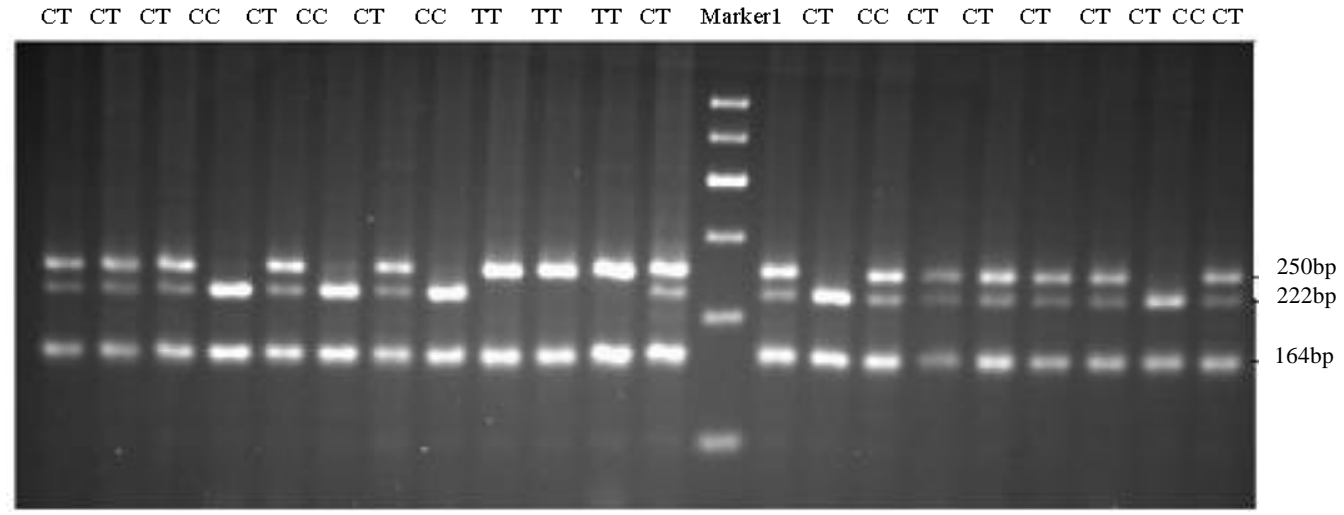

Marker $1(600,500,400,300,200$ and $100 \mathrm{bp})$

Fig. 1: The Hin6I. PCR-RFLP analysis within PROP1 gene in Hainan black goat

Table 2: The allelic and genotypic frequencies, diversity indexes for PROP1 -Hin6 in Hainan black goat

\begin{tabular}{|c|c|c|c|c|c|c|}
\hline \multirow[b]{2}{*}{ Types } & \multicolumn{3}{|c|}{ No. of genotypes } & \multirow[b]{2}{*}{ Total } & \multicolumn{2}{|c|}{ Allelic frequencies } \\
\hline & $\mathrm{CC}$ & CT & TT & & $\mathrm{C}$ & $\mathrm{T}$ \\
\hline \multirow[t]{2}{*}{ Numbers } & 88 & 140 & 56 & 284 & 0.556 & 0.444 \\
\hline & \multicolumn{3}{|c|}{ Genetic diversity indexes } & & & \\
\hline Types & $\mathrm{H}_{\mathrm{k}}$ & $\mathrm{N}_{\ell}$ & PIC & \multicolumn{2}{|c|}{ Gene variation sample } & $\chi^{2}$ \\
\hline Numbers & $\begin{array}{l}0.50 \\
6\end{array}$ & $\begin{array}{l}0.49 \\
4\end{array}$ & 1.975 & 4.36 & & $5.618 \times 10^{4}$ \\
\hline
\end{tabular}

information contents) was 0.4940 (Table 1 ). The analyzed population was in the Hardy-Weinberg equilibrium $(\mathrm{p}>0.05)$.

Differences of allelic and frequencies between Hainan black goat and the other breeds: Combining with the previously reported genotypic frequencies at Hin6I locus in Inner Mongolia White Cashmere goat (IMWC), Shaanbei White Cashmere goat (SBWC), Xinong Sannen dairy goat ( $\mathrm{Sa}$ ), Laoshan dairy goat (LS), Guanzhong dairy Goat (GZ) (Lan et al., 2009), differences of genotypic and allelic frequencies at PROP1-Hin6I locus among Hainan black goat and the reported five other breeds were calculated. The significant difference was found among all analyzed populations based on a Chi-square test $\left(\chi^{2}=524.739, \mathrm{df}=10, \mathrm{p}<0.001\right)$. Moreover, significant differences of allelic frequencies among all analyzed populations were also found $\left(\chi^{2}=600.606\right.$, df $=5$, $\mathrm{p}<0.001)$. Besides, genotypic frequencies of $\mathrm{HNBG}$ population showed significant differences when compared with other goat breeds $(p<0.001)$ as well as significant differences of allelic frequencies of $\mathrm{HNBG}$ when compared with other goat breeds $(\mathrm{p}<0.001)$ (Table 3).

Assocociation of PROP1-Hin6I polymorphism with growth traits in Hainan black goat: The establishment of relationships between different genotypes of PROP1-
Hin6I and body weight and body sizes was done in 284 Hainan black goats (Table 4). Significant relationships between different genotypes and Body Length (BL), Chest Circumferene (ChC), Chest Width (ChW) and Cannon Circumference index $(\mathrm{CaCI})$ were found $((\mathrm{p}<0.05)$. The individuals with genotype CT demonstrated better Body Length (BL), Chest Circumferene (ChC) and Cannon Circumference Index $(\mathrm{CaCI})(\mathrm{p}<0.05)$ when compared with those with the genotype CC. A significant statistical associations of different genotypes with chest width revealed that individuals with genotypes TT and CT had wider chest than that of genotype CC $(\mathrm{p}<0.05)$.

Due to the somatotropic axis involving hormones, growth factors and other regulatory proteins plays a key role in complicated growth system of goat, these genes encoding for Growth Hormone (GH), GH Receptor (GHR), Prolactin (PRL), Prolactin Receiptor (PRLR), transcription factor PIT1, transcriptor STAT5 Insulin-like Growth Gactor 1(IGF1) and perhaps presently unknown genes coding for $\mathrm{GH}$ signal transduction pathways, reponsibly contribute to candidate genetics markers for quanlititative traits in goat growth and development (Dario et al., 2009).

A large number of evidences of signicant associations of before mentioned genes with growth traits verified their contribution in MAS. For examples in GH gene, three SNPs (GU003881:g.A112G, GU003881:g.C142T and GQ994429:g. C214T) were significantly associated with body weight, withers height, body length and chest girth in goat $(\mathrm{p}<0.05)$ as well as other two SNPs (GU003880:g.C214T and GQ994430:g.C266A) were also significantly associated with body weight, body length and chest girth ( $\mathrm{p}<0.05$ ) (An et al., 2010). In GH gene of Boer goat bucks, AA genotype within A781G (Ser/Gly35) and A1575G (Leul47) loci significantly resulted in a significant decrease in birth chest girth $(\mathrm{p}=0.03)$ and weaning weight $(\mathrm{p}=0.014)$ comparing to $\mathrm{AB}$ genotype 
Table 3: Differences analysis of genotypic and allelic frequencies at PROP1-Hin 6 locus among Hainan black goat and the reported other breeds

\begin{tabular}{|c|c|c|c|c|c|c|}
\hline Breeds & $\mathrm{HNBG}$ & חMWC & SBWC & $\mathrm{Sa}$ & $\mathrm{LS}$ & GZ \\
\hline $\mathrm{HNBG}$ & - & $\begin{array}{l}* * * 420.46(d f=2) \\
(p<0.001)\end{array}$ & $\begin{array}{l}* * 127.83(\mathrm{df}=2) \\
(\mathrm{p}<0.001)\end{array}$ & $\begin{array}{l}* * 75.12(d f=2) \\
(p<0.001)\end{array}$ & $\begin{array}{l}* * 96.03(\mathrm{df}=2) \\
(p<0.001)\end{array}$ & $\begin{array}{l}* * 60.31(\mathrm{df}=2) \\
(p<0.001)\end{array}$ \\
\hline IMWC & (Fisher's exact test) $p<0.001$ & - & $* * 12.907(p=0.000)$ & $0.59(p=0.444)$ & $0.77(\mathrm{p}=0.380)$ & $1.79(\mathrm{p}=0.181)$ \\
\hline SBWC & (Fisher's exact test) $p<0.001$ & $* * 12.050(\mathrm{p}=0.001)$ & - & $1.43(\mathrm{p}=0.233)$ & $* 6.338(\mathrm{p}=0.012)$ & $0.40(\mathrm{p}=0.525)$ \\
\hline $\mathrm{Sa}$ & (Fisher's exact test) $\mathrm{p}<0.001$ & $0.55(\mathrm{p}=0.457)$ & $1.28(\mathrm{p}=0.257)$ & - & $1.49(\mathrm{p}=0.222)$ & $0.18(\mathrm{p}=0.668)$ \\
\hline LS & (Fisher's exact test) $\mathrm{p}<0.001$ & $0.73(\mathrm{p}=0.394)$ & $* 5.773(\mathrm{p}=0.016)$ & $1.41(\mathrm{p}=0.235)$ & - & $2.60(\mathrm{p}=0.107)$ \\
\hline$\underline{\mathrm{GZ}}$ & (Fisher's exact test) $\mathrm{p}<0.001$ & $1.68(\mathrm{p}=0.195)$ & $0.36(p=0.548)$ & $0.17(\mathrm{p}=0.681)$ & $2.45(p=0.118)$ & - \\
\hline
\end{tabular}

$\chi^{2} / \mathrm{P}$ of distribution of genotypes frequency between two breeds (the up-triangle) $\chi^{2} / \mathrm{P}$ of distribution of different allele numbers between two populations (The down-triangle); $\mathrm{HNBG}=$ Hainan Black Goat; IMWC = Inner mongolia White Cashmere Goat; SBWC $=$ Shaanbei White Cashmere goat; Sa = Xinong sannen dairy goat; $\mathrm{LS}=$ Laoshan dairy goat; $\mathrm{GZ}=$ Guanzhong dairy goat

Table 4: The effects of the PROP1-Hin6I polymorphism on body weight and body sizes in Hainan black goat

\begin{tabular}{|c|c|c|c|c|}
\hline Traits & TT genotype $(n=56)$ & CT genotype $(n=140)$ & CC genotype $(n=88)$ & $\mathrm{p}$ value \\
\hline BW (kg) & $28.938 \pm 5.9660$ & $28.803 \pm 7.2450$ & $26.928 \pm 7.1590$ & $>0.050$ \\
\hline $\mathrm{BH}(\mathrm{cm})$ & $53.106 \pm 3.9740$ & $52.652 \pm 4.1320$ & $52.250 \pm 4.3290$ & $>0.050$ \\
\hline $\mathrm{BL}(\mathrm{cm})$ & $56.117 \pm 4.5070$ & $56.339 \pm 4.3600^{\mathrm{a}}$ & $54.843 \pm 4.6300^{b}$ & 0.017 \\
\hline $\mathrm{ChC}(\mathrm{cm})$ & $72.396 \pm 5.9720$ & $72.620 \pm 6.7660^{\mathrm{a}}$ & $70 \mathrm{~b} .566 \pm 6.2410$ & 0.023 \\
\hline $\mathrm{ChD}(\mathrm{cm})$ & $26.515 \pm 2.0670$ & $26.471 \pm 2.5460$ & $26.239 \pm 2.3270$ & 0.050 \\
\hline ChW $(\mathrm{cm})$ & $15.165 \pm 1.5880^{c}$ & $15.055 \pm 2.0220^{\circ}$ & $14.166 \pm 1.6630^{\mathrm{a}}$ & 0.002 \\
\hline $\mathrm{HuW}(\mathrm{cm})$ & $13.679 \pm 1.4140$ & $13.735 \pm 1.3590$ & $13.458 \pm 1.3590$ & $>0.050$ \\
\hline $\mathrm{CaC}(\mathrm{cm})$ & $7.8692 \pm 0.675$ & $7.7879 \pm 0.730$ & $7.6988 \pm 0.775$ & $>0.050$ \\
\hline BLI (\%) & $105.930 \pm 8.0730$ & $107.320 \pm 8.0320$ & $105.250 \pm 8.0570$ & $>0.050$ \\
\hline ChCI $(\%)$ & $136.55 \pm 9.54100$ & $138.160 \pm 10.770^{\mathrm{a}}$ & $135.310 \pm 9.4300^{b}$ & 0.045 \\
\hline $\mathrm{CaCI}(\%)$ & $14.869 \pm 1.3890$ & $14.832 \pm 1.3440$ & $14.581 \pm 2.0580$ & $>0.050$ \\
\hline $\mathrm{TI}(\%)$ & $129.270 \pm 8.8570$ & $129.040 \pm 9.2400$ & $128.930 \pm 9.0310$ & $>0.050$ \\
\hline
\end{tabular}

while CC genotype contributed to weaning height $(\mathrm{p}=0.04)$ greater than CD genotype. Especially when in combination, AACD genotype in GH gene was undesired for lower scores in a series of growth traits including body weight, length, height and chest girth at birth and weaning, as well as the pre-weaning daily gain and body weight at age of 11 months (Hua et al., 2009). In GH gene interaction of $\mathrm{GH}$ gene polymorphisms ( $\mathrm{AA}, \mathrm{AB}$ and $\mathrm{BB}$ genotypes) with body weight and measures of endocrine function in Japanese black calves at 10 months of age were revealed and the average body weight for the BB genotype was significantly lower $(\mathrm{p}=0.0017$, ANOVA) than those for the AA and AB genotypes.

In GHR gene, significant associations between the AluI (N/N) genotype of the GHR/AluI polymorphism and lower weight gain and body weight at slaughterwere observed $(\mathrm{p}<0.05)$, although a confounding between genotypes and genetic groups may have occurred (Curi et al., 2006).

In PIT1 gene, a significant statistical association of PIT1-DdeI polymorphism (TCT(241Ser) $>$ TCG(Ser)) with weight results were founded in goat $(\mathrm{p}<0.05)$ and D1D1 genotype had higher weight in 1 year old (Lan et al., 2007a). A significant statistical associations of PIT1-AluI polymorphism (AGT(279Ser)>AGC(279Ser)) with birth weight in goat were revealed $(\mathrm{p}<0.05)$ and genotype TT was recommended to be a molecular markers for superior birth weight in goat (Lan et al., 2007b). Zhao et al. (2000) reported that PIT-1/Hinf I polymorphism appears to affect growth traits in Angus cattle as well as Xue et al. (2006) and Reza et al. (2010) reported similar polymorphism of
PIT1 gene and its effect on the growth traits in Nanyang cattle. In STAT5A gene, significant relationships between STAT5A/AvaI polymorphism and growth performance traits including the animals' Body Weights at 180 days (BW180), 270 days (BW270), 360 days (BW360) and 450 days (BW450) days were founded (Dario et al., 2009).

In IGF-1 gene, body length of Xinong Saanen dairy goat with CG genotype within D26119.2:g.5752G $>$ C locus was significantly longer than in the others and Chest Circumference (ChC) of Guanzhong dairy goat goats with the GG genotype was the largest of the three genotypes whereas $\mathrm{ChC}$ for individuals with CG genotype was larger than that for $\mathrm{CC}$ carriers ( $\mathrm{p}<0.05$ ) (Deng et al., 2010).

Considering the crucial role in PROP1-PIT1GH/PRL/TSH pathway and the association of mutations of GH, GHR, PRL, PRLR and PIT1, PROP1 can be considered as an important and potential candidate gene for goat growth traits selection and breeding through Marker Assisted Selection (MAS). Therefore in this study, the polymorphism of goat PROP1 gene was detected and its associations with growth traits also will be evaluated.

In the present research, the PCR-SSCP method was carried out to scan the preminary polymorphism and DNA sequencing was utilized to verify it. The result revealed that the AF453512:g.1795C > T SNP resulting in GCG (Ala) > GTA (Val) at position 79 aa of the PROP1 (226 aa) complied with the previous reported (Lan et al., 2009). The present goat PROP1 mutation was very similar to the ovine PROP1 gene A79A mutation (AY533708: g: $1402 \mathrm{G}>\mathrm{A})$. Both goat PROP1 mutation and ovine PROP1 
mutation can be distinguished by Hin6 PCR-RFLP which differred in that genotype GG $(167+126+97+28 \mathrm{bp})$ and genotype GA $(167+154+126+97+28$ bp) was shown in ovine Hin6I PCR-RFLP analysis. However, the genetic variation spectrum of goat PROP1 greatly differed from bovine PROP1 mutations. In bovine, four SNPs (AF453512:g.349G $>$ A, 381 T>A, 508C $>$ A and 511T $>$ A) distributed in in intron 1 and nt457 was located in nt69 of exonl and resulted in a silent mutation in 23 position. Moreover, the A79V mutation is close to the mutation of human PROP1 R73C which was one of the four hot spot mutations in human and associated with the CPHD implying the revealed mutation may affect the expression of $\mathrm{GH}, \mathrm{PRL}$ or $\mathrm{TSH}$ and production significant influence on growth traits.

In this study, the novel genotype TT was found and showed relative high frequency which was greatly diffent from the previous report (Lan et al., 2009). Compared with those of Inner Mongolia White Cashmere goat (IMWC), Shaanbei White Cashmere goat (SBWC), Xinong Sannen dairy goat ( $\mathrm{Sa}$ ), Laoshan dairy goat (LS), Guanzhong dairy goat (GZ), the present genotype TT and allele T demonstrated significantly higher frequencies $(p<0.01)$. These imply that there are significant differences among dairy, wool and meat goat breeds concerning the alleles and the genotypes of Hin6I locus. For example, the frequency of the $\mathrm{T}$ allele in meat goats (HNBG) is higher when compared to those of wool (IMWC and SBWC) and dairy goat ( $\mathrm{Sa}, \mathrm{LS}$ and GZ). Since, many of the analyzed breeds have been selected for meat production we can suppose that intensive selection for weight gain could have indirectly influenced PROP1 allele frequencies.

However, further studies should be carried out with goat selected for wool and milk production in order to compare the allele frequencies.

Association analysis between the three genotypes (CC, CT and TT) and body weitght and body size revealed an significant associations of PROP1 gene polymorphisms with Body Length (BL), Chest Circumferene (ChC), Chest Width (ChW) and Cannon Circumference Index (CaCI) in Hainan black goat. It gives a clue that the PROP1 gene produces significant genetic effect on growth traits which can be explained by the following causes. First, the Hin6 polymorphism of goat PROP1 resulting in a missense mutation maybe changes the protein charateristics. Second, the current mutation regulates the expression of PIT1 or GH genes which possibly and really affect the growth traits. Third, the current mutation may be linked with the major gene producting significant influence on growth trait. Based on the before mentioned description, the PROP1 gene is a potential candidate gene for growth traits in MAS. The genotype CT at the Hin6 polymorphism locus could be used as a molecular marker for superior body sizes. The genotypes CT and TT could be used as a molecular marker for superior Chest Width (ChW). Furthermore, this study will be of practical use for the improvement of Chinese native meat goats and the local breeding of those with higher status.

\section{CONCLUSION}

A significant statistical associations of different genotypes with chest width revealed that individuals with genotypes TT and CT had wider chest than that of genotype $\mathrm{CC}(\mathrm{p}<0.05)$. Therefore, the PROP1 gene could be used as a molecular marker for superior growth traits such as body sizes and Chest Width (ChW).

\section{ACKNOWLEDGEMENTS}

This research was supported by Nonprofit Research Institutions of Chinese Central Committee for Basic Scientific Research Special Fund Operating Expenses (No. PZS036), the Young Topnotch Researcher Support Project of Northwest A and F University (No. QNGG-2009007) and the National 863 Program of the P.R. China (No. 2008AA10Z138).

\section{REFERENCES}

Allan, M.F., R.M. Thallman, R.A. Cushman, S.E. Echternkamp and S.N. White et al., 2007. Association of a single nucleotide polymorphism in SPP1 with growth traits and twinning in a cattle population selected for twinning rate. J. Anim. Sci., 85: 341-347. An, X.P., J.X. Hou, L.X. Wang, G. Li and J.G. Wang et al., 2010. Novel polymorphisms of the growth hormone gene and their effect on growth traits in Chinese goats. Meat Sci.

Carvalho, L., R.D. Ward, M.L. Brinkmeier, M.A. Potok, A.H. Vesper and S.A. Camper, 2006. Molecular basis for pituitary dysfunction: Comparison of Propl and Pit1 mutant mice. Dev. Biol., 295: 340-340.

Curi, R.A., D.A. Palmeiri, L. Suquiawa, A.L.J. Ferraz and H.N. de Oliveria et al., 2006. Effects of GHR gene polymorphisms on growth and carcass traits in Zebu and crossbred beef cattle. Livestock Sci., 101: 94-100.

Dario, C., M. Selvaggi, D. Carnicella and G. Bufano, 2009. STAT5A/AvaI polymorphism in Podolica bulls and its effect on growth performance traits. Livestock Sci., 123: 83-87.

Davis, S.W., F. Castinetti, L.R. Carvalho, B.S. Ellsworth and M.A. Potok et al., 2010. Molecular mechanisms of pituitary organogenesis: In search of novel regulatory genes. Mol. Cell. Endocrinol., 323: 4-19. 
Deng, C., R. Ma, X. Yue, X. Lan, H. Chen and C.Z. Lei, 2010. Association of IGF-I gene polymorphisms with milk yield and body size in Chinese dairy goats. Genet. Mol. Biol., 33: 266-270.

Gupta, N., S.P.S. Ahlawat, D. Kumar, S.C. Gupta, A. Pandey and G. Malik, 2007. Single nucleotide polymorphism in growth hormone gene exon-4 and exon-5 using PCR-SSCP in Black Bengal goats-a prolific meat breed of India. Meat Sci., 76: 658-665.

Hua, G.H., S.L. Chen, J.N. Yu, K.L. Cai and C.J. Wu, et al., 2009. Polymorphism of the growth hormone gene and its association with growth traits in Boer goat bucks. Meat Sci., 81: 391-395.

Katoh, K., S. Kouno, A. Okazaki, K. Suzuki and Y. Obara, 2008. Interaction of $\mathrm{GH}$ polymorphism with body weight and endocrine functions in Japanese black calves. Domestic Anim. Endocrinol., 34: 25-30.

Lan, X.Y., C.Y. Pan, H. Chen, C.Z. Lei and L.S. Hua et al., 2007a. Ddel polymorphism in coding region of goat POU1F1 gene and its association with production traits. Asian-Aust. J. Anim. Sci., 20: 1342-1348.

Lan, X.Y., C.Y. Pan, H. Chen, C.L. Zhang and J.Y. Li et al., 2007b. An AluI PCR-RFLP detecting a silent allele at the goat POU1F1 locus and its association with production traits. Small Rum. Res., 73: 8-12.

Lan, X.Y., C.Y. Pan, L.Z. Zhang, M. Zhao, C.L. Zhang, C.Z. Lei and H. Chen, 2009. A novel missense (A79V) mutation of goat PROP1 gene and its association with production traits. Mol. Biol. Reports, 36: 2069-2073.

Lan, X.Y., C.Y. Pan, S.R. Hu and H. Chen, 2008. PCR-SSCP and Hin6I PCR-RFLP detecting novel anonymous SNPs within ovine PROP1 gene. Arch. Tierz., 51: 622-623.

Li, S., E.B. Crenshaw III, E.J. Rawson, D.M. Simmons, L.W. Swanson and M.G. Rosenfeld, 1990. Dwarf locus mutants lacking three pituitary cell types results from mutations in the POU-domain gene Pit-1. Nature, 347: 528-533.

Pan, C.Y., X.Y. Lan, H. Chen, L.S. Hua, Y.K. Guo, B. Zhang and C.Z. Lei, 2007. Five novel single nucleotide polymorphisms (SNPs) of the prohet of PIT1 (PROP1) gene in bovine. Arch. Tierz., 50: 421-423.
Pfaffle, R.W., G.E. Dimattia, J.S. Parks, M.R. Brown and J.M. Wit et al., 1992. Mutation of the POU-specific domain of Pit-1 and hypopituitarism without pituitary hypoplasia. Science, 257: 1118-1121.

Reza, N., A. Nader, S.F. Adbdolreza, S.M.N. Amin, H. Parivash and J. Arash, 2010. Comparison of DNA polymorphism of bovine pituitary-specific transcription factor and leptin gene between Iranian Bos Indicus and Bostaurus cattle using PCR-RFLP. J. Anim. Vet. Adv., 9: 1660-1663.

Sambrook, J. and D.W. Russell, 2002. Translated by Huang Pei-tang. Molecular Cloning: A Laboratory Manual. 3rd Edn., China Science Press, Beijing, pp: 629-630.

Shibahara, H., N. Ikeshita, Y. Sugiyama, K. Toda and D. Yamamoto et al., 2010. W194XPropl and S156insTProp1, both of which have intact DNAbinding domain, show a different DNA-binding activity to the Prop1-binding element in human Pit-1 gene. Mol. Cell. Endocrinol., 323: 167-171.

Sun, H.S., L.L. Anderson, T.P. Yu, K.S. Kim, J.Klindt and C.K. Tuggle, 2002. Neonatal Meishan pigs show POU1F1 genotype effects on plasma GH and PRL concentration. Anim. Reprod. Sci., 69: 223-237.

Wu, W., J.D. Cogan, R.W. Pfaffle, J.S. Dasen and H. Frisch et al., 1998. Mutations in PROP1 cause familial combined pituitary hormone deficiency. Nature Genet., 18: 147-149.

Xekouki, P., A. Sertedaki, S. Livadas, M. Argyropoulou and A. Voutetakis, 2007. PROP1 gene mutations and pituitary size: A unique case of two consecutive cycles of enlargement and regression. Hormone Res., 67: 109-113.

Xue, K., H. Chen, S. Wang, X. Cai and B. Liu et al., 2006. Effect of genetic variations of the POU1F1 gene on growth traits of Nanyang cattle. Acta Genet. Sin., 33: 901-907.

Zhao, Q., M.E. Davis and H.C. Hines, 2000. Association of two Pit-1 gene polymorphisms with growth rate in beef cattle. J. Anim. Sci., 78: 77-77. 